not in favour of coercive legislation. Galton's vision of eugenics was more abstract and benign than that which emerged in the United States and Germany in the first four decades of the twentieth century. As Galton's final obsession, eugenics became the crowning point of his long career, and the work for which he is probably most frequently remembered.

Admirable though it is in many ways, the book has flaws. Gillham tries at times to cast Galton's ideas in present-day terms that make them sound more modern than they really are. For example, Galton's statement that the "quasi-independent units which the body is made up of have a separate origin, or germ" is not really equivalent, as Gillham claims, to "genes specifying individual proteins"; nor is Galton's explanation of reversion equivalent to recessive mendelian genetics. I understand the author's desire to make apparently opaque and confused theories comprehensible to the modern reader, but such policy does a disservice to both the reader and to Galton. That Galton found little of interest in Mendel's theory after its rediscovery in 1900, for example, attests to the very different conceptual understanding of heredity under which he and his contemporaries, including Darwin, were working.
All in all, this is a highly readable and valuable contribution to the fields of both biography and the history of science. Gillham has done a creditable job in placing Galton in his Victorian social and intellectual environment, and in showing where he was constricted by — and able to transcend his own time and place.

Garland E. Allen is in the Department of Biology, Washington University in St Louis, Campus Box 1137, St Louis, Missouri 63130, USA.

\section{State-of-the-art oceanography}

\section{Ocean Circulation \& Climate: Observing and Modelling the Global Ocean \\ edited by Gerold Siedler, John Church \& John Gould \\ Academic: 2001.715 pp. \$99.95, £65.95 \\ Detlef Quadfasel}

Ocean science has made a big leap forward during the past decade. Developments outside the field itself, such as increasing computer power and new measurement

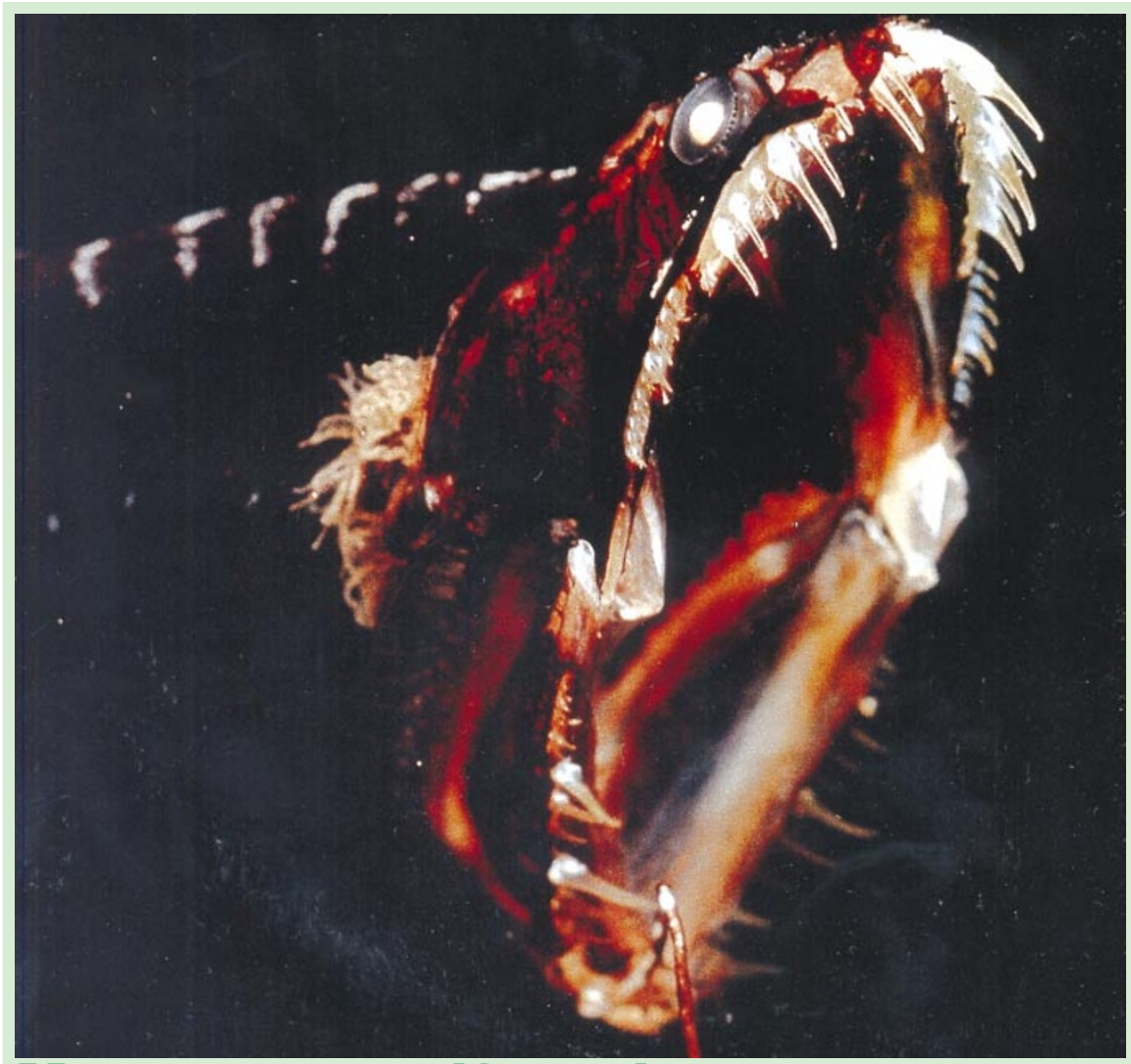

\title{
Monstrous manifestations
}

Beware this black dragonfish (Idiacanthus antrostomus), which uses a phosphorescent lure to attract its prey. The image is taken from Creatures of the Deep: In Search of the Sea's
"Monsters" and the World They Live In by Erich Hoyt (Firefly, \$40). The book explores the domain far below the waves and reveals that monsters "are alive and well and living in the deep". technology, have driven much of the advance. The global ocean can now be observed from space and in situ with autonomous moored and floating devices, and marine climate variability can be modelled on this basis. The societal interaction in oceanography has also improved, due primarily to the World Ocean Circulation Experiment (WOCE), carried out during the 1990s, which was the first truly global scientific undertaking to attempt to understand (and eventually predict) the role played by the oceans in the Earth's climate. The effort was global not only in terms of scientific coverage and participation by scientists, but also in its data-sharing policy. The development of modern electronic communications also greatly contributed to its success. Ocean Circulation \& Climate, an account of the results of this experiment, is not just a cruise report but provides a comprehensive view into the state of the art of blue-ocean research.

This modern view of the ocean is communicated in some 30 articles, covering different technical, regional, scientific and political-philosophical aspects of WOCE and the ocean. The outline of the book largely follows the organizational structure of the experiment with its working groups and panels, but there are also discussion chapters integrating the results in a broader sense. This strategy has the advantage that individual subjects are covered by experts in each field. On the other hand, its disadvantage is that it has the character of a conference proceedings report, with a concomitant variability in scope and quality of the individual contributions.

WOCE has undoubtedly proved (again) that the ocean is turbulent and highly variable, and that the historical view of a largescale and quasi-steady dynamic balance is inadequate, if not totally misleading. Variability exists on all timescales, and has been quantified in the surface drifter and float programmes, with the moored current meter records and the satellite altimetry data, for the first time providing global statistics. Small-scale processes such as mixing along a density gradient are explored and shown to be associated with strong spatial and temporal variability. Its influence on the large-scale circulation is just beginning to emerge, but may lead to a radical change in ocean modelling.

WOCE has also shown that the large-scale circulation itself can undergo rapid changes in response to atmospheric forcing - much faster than previously thought. The intense observational programme in the North Atlantic has documented this coupling through the processes of convection and overflows, and has provided a basis for the study of oceanic variability associated with the Arctic or North Atlantic Oscillations. Here the interaction between the 


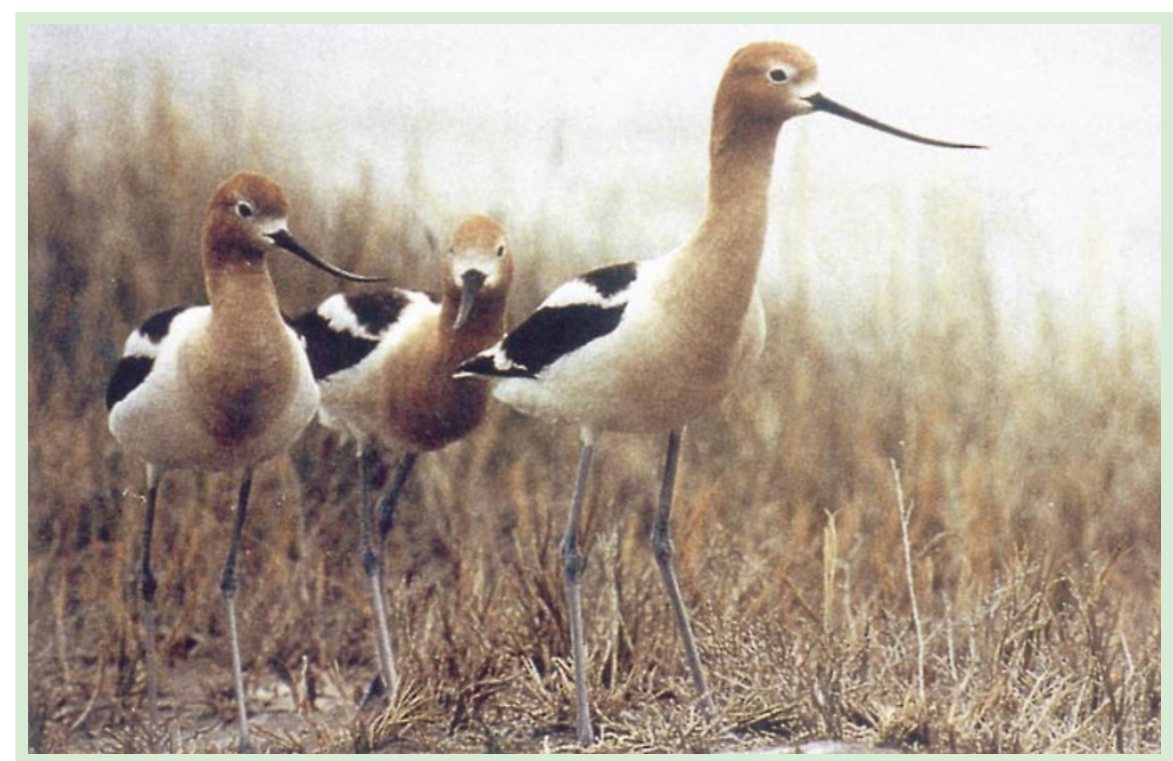

\section{Down on the shore}

American avocets (Recurvirostra americana) can be identified by their upwardly curving beaks and contrasting plumage. The numbers of these gregarious shoreline birds are under threat from loss of their wetland habitat in the western United States. The avocets are just one of the 72 species of bird described in Common Coastal Birds of Florida and the Caribbean by David W. Nellis

(Pineapple Press, \$21.95). atmosphere and the deep ocean is fast, and ranges from years to decades rather than centuries or longer. High-quality hydrographic observations of water masses over the globe have identified the variability in the ocean's interior and allowed quantification of the impact of varying atmospheric forcing. A series of chapters is devoted to the analysis of hydrographic data, which constituted the core of WOCE. From these, one can conclude that the initial WOCE goal of compiling a coherent global oceanic description has led to better documentation of the ocean's variability. The development of models for predicting associated climate change is well under way.

A third message conveyed in the book is probably as old as physics itself: that adequate observations are a prerequisite to test, accept or refute hypotheses, theories and models. Climate dynamics are highly nonlinear, and the predictive skill of any model can only be judged if adequate and long-term observations are available. The search for methods for determining longterm changes in the ocean circulation has been, and remains, the second goal of the programme. Many technical advances have been made, and the ideas about new and cheap measurement strategies are described in several of the book's chapters. Much of this has already been implemented in follow-up projects under the umbrella of the World Climate Research Programme. The necessity of extending the time series of observations relating to climate is reiterated throughout, and it can only be hoped that politicians and science administrators in funding agencies will take the opportunity to read this book and learn about the ocean.

Who else is a potential reader? The review character makes Ocean Circulation o Climate attractive for graduate students in Earth sciences and climate researchers in general, and of course the WOCE community itself. As an overview containing almost 100 pages of up-to-date references, this book will be an invaluable tool for those engaged in climate research and teaching. It is certainly not a book that one reads from beginning to end, but one that will be picked up readily when questions about ocean circulation arise.

DetlefQuadfasel is in the Department of Geophysics, Niels Bohr Institute for Astronomy, Physics and Geophysics, University of Copenhagen, Juliane Maries Vej 30, 2100 Copenhagen, Denmark.

\section{More on the oceans}

The Oceans and Rapid Climate Change: Past, Present and Future

edited by Dan Seidov, Bernd J. Haupt

\& Mark Maslin

American Geophysical Union, $\$ 60$

Wind Stress Over the Ocean

edited by Ian S. F. Jones \& Yoshiaki Toba

Cambridge University Press, $£ 50, \$ 80$

Great Waters: An Atlantic Passage

by Deborah Cramer

W. W. Norton, £22, $\$ 27.95$

\section{Name that plant

\author{
Guide to Standard Floras \\ of the World \\ by David G. Frodin \\ Cambridge University Press: 2001. 1,100 pp. \\ $£ 150, \$ 240$
}

\section{P. F. Stevens}

Here, in a mere 1,000 pages or so, we have a guide to the plants of the world, past and present. David Frodin focuses on standard floras - a catalogue of plants of a defined area with descriptions, but excluding lists of weeds - past and present, and his is by far the most comprehensive treatment of the subject available.

There are, clearly, large gaps in our knowledge about the world's plants. For example, if you want to know about the plants to be found in Baluchistan, there is only I. H. Burkill's A Working List of the Flowering Plants of Baluchistan, published almost a century ago. Moreover, as Frodin notes, both his book and floras as a discipline in general are at a crossroads, and it is not clear what form either will take in the future. Frodin's book was current to 2000, but it is easy to imagine an online version being continually updated.

The Guide to Standard Floras will be invaluable as a library resource. Three introductory chapters lead to the body of the work, a geographical listing of floras. The lists of plants in the major geographical areas identified by Frodin - for example, divisions, areas often continental in size are preceded by informative summaries of the state of our knowledge of the plants in them. The book is made navigable by several indexes - geographical names, the numbers referring to Frodin's geographical system (not pages), and authors of floras, although it is somewhat confusing because Frodin makes references to both page numbers and geography. In general, the indexes are complete, although there is no mention of the island of Bougainville, and not one of the 14 authors of the remarkable Flora da Reserva Ducke (one of a new breed of floras) is mentioned; this has more than 20,000 photographs for some 2,200 species, and emphasizes the use of vegetative features in identification.

The introductory chapters clearly indicate the complex institutional, national and professional constraints that have shaped the way floras have developed, and also demonstrate how web technology is straining the conventional format of the flora. In the past, floras have included identification aids, detailed descriptions of plants, lists of localities, specimens cited, literature, 